\title{
Preliminary Scoring Template of a Modified Landing Error Scoring System
}

\section{Ivana Hanzlíková ${ }^{*}$, Jim Richards ${ }^{2}$ and Kim Hébert-Losier ${ }^{1}$}

${ }^{1}$ Division of Health, Engineering, Computing and Science, Te Huataki Waiora School

of Health, Adams Centre for High Performance, University of Waikato, New Zealand

${ }^{2}$ Allied Health Research Unit, University of Central Lancashire, United Kingdom

*Corresponding Author: Ivana Hanzlíková, Division of Health, Engineering, Computing and Science, Te Huataki Waiora School of Health, Adams Centre for High

Performance, University of Waikato, New Zealand. E-mail: xhanzlikova@gmail.com
Received: December 29, 2021

Published: January 18, 2022

(C) All rights are reserved by Ivana

Hanzlíková., et al.

\section{Abstract}

Background: The Landing Error Scoring System (LESS) identifies participants displaying potentially high-risk movement patterns during a double-leg jump-landing (DLJL) task. However, the DLJL has been criticized for not reflecting injury-prone situations in sport. The biomechanics and perceived difficulty of a rotated single-leg jump-landing (SLJ $\mathrm{L}_{\text {rot }}$ ) task have shown stronger associations with sport-specific cutting maneuvers than DLJL. Therefore, the SLJL $\mathrm{rot}_{\text {may }}$ be a better suited task than the DLJL to assess landing "errors".

Objectives: Present a preliminary scoring template of a modified LESS applied to a SLJL $\mathrm{L}_{\text {rot }}$ task.

Design: Cross-sectional study.

Methods: Whole-body motion was recorded for 42 young active participants (25 males and 17 females) using a three-dimensional infrared camera system during DLJL and SLJL $\mathrm{r}_{\text {rot }}$ tasks. Ankle, knee, hip, and trunk angles corresponding to the original LESS items were extracted for dominant and non-dominant legs from both tasks. Based on the differences in kinematic values between tasks, original LESS thresholds, and current scientific evidence, the original LESS items from the DLJL were modified to suit the SLJL rot $_{\text {task. }}$ Results: A preliminary scoring template of a modified LESS applied to a SLJL ${ }_{\text {rot }}$ task was developed, including operational definitions of errors and relevant thresholds. The preliminary template consists of 13 items. The minimum and maximum scores are 0 and 12 errors, respectively, with higher scores indicating poorer landing biomechanics.

Conclusions: The modified LESS may be an appropriate clinical screening tool for assessing sport-related non-contact lower extremity injury risk in athletes. The proposed template and thresholds require further scientific validation.

Keywords: Injury Risk; Screening Tool; Sport Injuries; Anterior Cruciate Ligament

\section{Highlights}

- $\quad$ Preliminary scoring template of modified LESS applied to SLJL $_{\text {rot }}$ task was developed

- $\quad$ Modified LESS may be an appropriate clinical sport-related injury risk screening tool

- $\quad$ The proposed template of modified LESS require further scientific validation

\section{Introduction}

The Landing Error Scoring System (LESS) is a movement-based injury risk screening tool first proposed by Padua and colleagues in 2009 [1]. The LESS was designed to identify participants displaying potentially high-risk biomechanical patterns for Anterior Cruciate Ligament (ACL) injury [1]. Clinicians evaluate frontal and sagittal plane videos of a double-leg jump-landing (DLJL) task and visually evaluate aberrant lower extremity and trunk kinematics between 
initial ground contact and peak knee flexion instances. Several studies have criticized the DLJL task used in the LESS, stating it is neither sport-specific nor sufficiently challenging to reveal movement patterns linked to non-contact lower-extremity injuries, and is poor for predicting ACL injuries [2,3]. Hanzlíková, Richards, Athens, Hébert-Losier [4] associated trunk and lower extremity kinematics between sport-specific unanticipated side-step cutting and jump-landing variations and compared perceived difficulty levels between tasks in young active individuals. The authors concluded that due to its subjective difficulty ratings and biomechanical associations with cutting movements, the rotated single-leg jumplanding $\left(\mathrm{SLJL}_{\mathrm{rot}}\right)$ task might be a more appropriate screening task for detecting at risk athletes involved in landing and cutting sports than the traditional DLJL task [4]. Hence, the SLJL rot $_{\text {may }}$ be better suited than the DLJL task to assess landing "errors" and more ecologically valid to identify athletes displaying movement patterns placing them at greater risk of lower-extremity injury during challenging sporting maneuvers. The original LESS scoring criteria need modifications to suit a SLJL $\mathrm{L}_{\text {rot }}$ task. This technical report presents a preliminary modified LESS scoring template applied to a SLJL $\mathrm{L}_{\text {rot }}$ task based on three-dimensional (3D) data collected in our laboratory, the original LESS thresholds [1,5], and current scientific evidence.

\section{Methods}

Forty-two physically active participants (25 males and 17 females) volunteered. A Health Research Ethics Committee approved the study protocol [HREC(Health)2018\#27], which adhered to the Declaration of Helsinki. All participants signed a written informed consent document before participating that explained the potential risks (i.e., delayed onset muscle soreness or risk of injury performing sport-related tasks).

Participants performed DLJL and SLJL $\mathrm{L}_{\text {rot }}$ tasks. The DLJL followed the original LESS protocol [1], requiring participants to jump forward from a $30-\mathrm{cm}$ high box with both feet, landing to a distance equal to $50 \%$ of their body height, and then immediately jumping upwards for maximal height (Figure 1). For the SLJL $\mathrm{L}_{\mathrm{rot}}$, the protocol was similar to the DLJL one, but participants rotated $90^{\circ}$ in the air before landing on one leg to a distance equal to $25 \%$ of their body height (Figure 1). After a familiarization period of on average two attempts per task, each participant completed three successful repetitions of DLJL and SLJL ${ }_{\text {rot }}$ tasks in a randomized order. The SLJL $L_{\text {rot }}$ was performed three times on the right and left lower extremity. The order of lower extremities was also randomized.

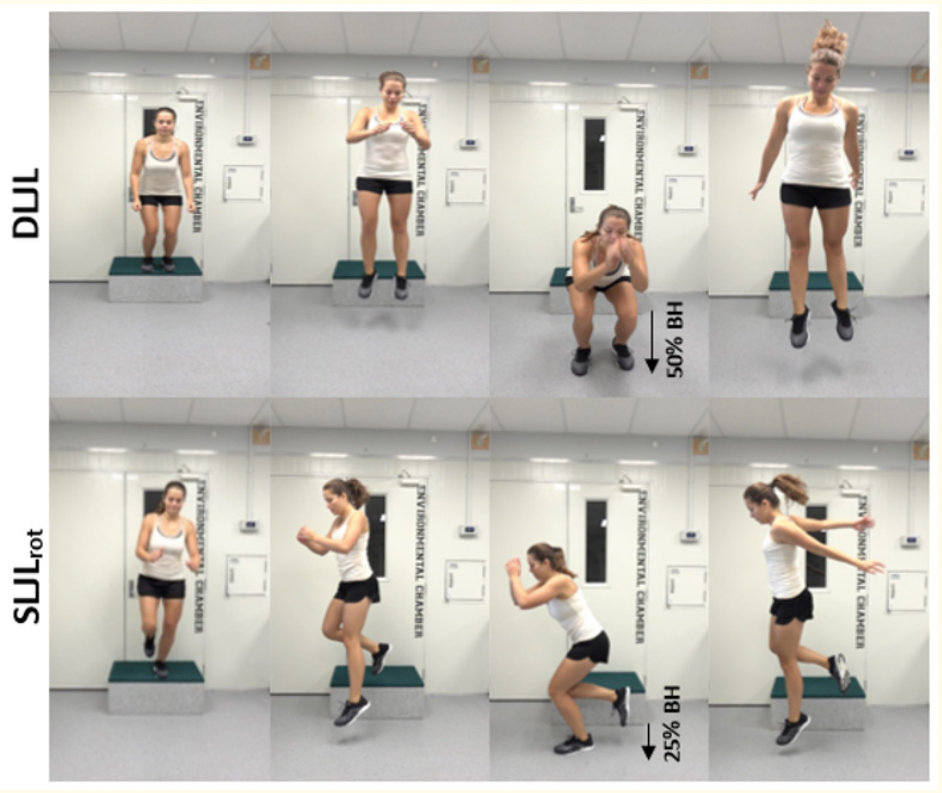

Figure 1: Double-leg jump-landing (DLJL) and rotated single-leg jump-landing (SLJLrot) tasks. BH, body height. 
Whole-body motion was recorded at $200 \mathrm{~Hz}$ during both tasks using an 8-camera 3D motion capture system (Oqus 700+ cameras) and software (Qualisys Track Manager v.2019.1, Qualisys AB, Gothenburg, Sweden). Forty-two $12.5 \mathrm{~mm}$ retroreflective markers and five clusters were taped onto the skin and shoes based on the Calibrated Anatomical System Technique [6], with one of the clusters positioned on the right side of the pelvis to improve segment tracking [4]. Data were exported to the. c3d format and processed using Visual3D Professional ${ }^{\mathrm{TM}}$ (v.6.01.36, C-Motion Inc., Germantown, Maryland, USA). A 13 rigid segment biomechanical model with six degrees of freedom at each joint was constructed. The local coor- dinates of all segments were derived from a static trial captured prior to the dynamic trials. Any marker data gaps, up to 10 frames (20 ms), were interpolated using a third order polynomial fit algorithm. A fourth order low-pass Butterworth filter with a cut-off frequency of $15 \mathrm{~Hz}$ was then applied to the data. Kinematic parameters were calculated using an XYZ cardan sequence, equivalent to the joint coordinate system [7]. Ankle, knee, hip, and trunk angles relevant to both the DLJL and SLJL $\mathrm{L}_{\text {rot }}$ items (Table 1) were extracted for the dominant and non-dominant leg. Inertial measurement units were placed above the lateral malleoli to define initial contact based on the peak vertical acceleration.

\begin{tabular}{|c|c|c|c|c|}
\hline \multirow[t]{2}{*}{ Items $s^{a}$} & \multicolumn{2}{|c|}{ Dominant leg } & \multicolumn{2}{|c|}{ Non-dominant leg } \\
\hline & DLJL & SLJL ${ }_{\text {rot }}$ & DLJL & SLJL $_{\text {rot }}$ \\
\hline Knee flexion: IC & $33.7 \pm 8.3$ & $18.3 \pm 5.6$ & $34.2 \pm 7.9$ & $17.6 \pm 5.4$ \\
\hline Hip flexion: IC & $38.9 \pm 13.1$ & $25.2 \pm 9.9$ & $38.7 \pm 12.3$ & $19.3 \pm 12.6$ \\
\hline Trunk flexion: IC & $16.4 \pm 7.5$ & $4.5 \pm 5.6$ & $16.2 \pm 7.4$ & $2.0 \pm 6.5$ \\
\hline Ankle plantar flexion: IC & $-13.1 \pm 7.9$ & $-18.8 \pm 7.5$ & $-12.0 \pm 8.1$ & $-16.9 \pm 6.6$ \\
\hline Medial knee position: IC & $1.4 \pm 4.6$ & $-1.6 \pm 3.8$ & $-0.9 \pm 4.9$ & $-2.9 \pm 4.3$ \\
\hline Lateral trunk flexion: IC & $-0.7 \pm 2.9$ & $7.3 \pm 4.7$ & $-0.7 \pm 3.0$ & $7.5 \pm 5.3$ \\
\hline Foot position: external rotation ${ }^{\mathrm{b}}$ & $-12.4 \pm 6.6$ & $-16.9 \pm 5.7$ & $-9.8 \pm 6.7$ & $-14.1 \pm 6.3$ \\
\hline Foot position: internal rotation ${ }^{\mathrm{b}}$ & $-0.8 \pm 6.1$ & $-3.1 \pm 6.4$ & $2.6 \pm 7.0$ & $0.0 \pm 6.7$ \\
\hline Knee flexion displacement ${ }^{b}$ & $74.4 \pm 14.9$ & $53.6 \pm 7.8$ & $72.0 \pm 14.2$ & $51.6 \pm 6.2$ \\
\hline Hip flexion displacement $t^{b}$ & $38.3 \pm 12.4$ & $27.5 \pm 9.1$ & $38.0 \pm 12.7$ & $31.3 \pm 10.3$ \\
\hline Trunk flexion displacement ${ }^{\mathrm{b}}$ & $22.8 \pm 11.4$ & $28.7 \pm 10.9$ & $22.7 \pm 11.6$ & $28.9 \pm 12.4$ \\
\hline Medial knee displacement $t^{\mathrm{b}, \mathrm{c}}$ & $-9.4 \pm 7.8$ & $-8.0 \pm 6.5$ & $-13.3 \pm 9.1$ & $-11.2 \pm 7.4$ \\
\hline Lateral trunk flexion displacement ${ }^{\mathrm{b}}$ & $3.3 \pm 1.2$ & $8.6 \pm 3.8$ & $3.3 \pm 1.4$ & $8.8 \pm 4.2$ \\
\hline
\end{tabular}

Table 1: Mean \pm standard deviation of angle values $\left({ }^{\circ}\right)$ of the Landing Error Scoring System items for the double-leg jump-landing (DLJL) and rotated single-leg jump-landing (SLJLrot) tasks.

IC: Initial Contact.

a. Positive values indicate flexion, dorsiflexion, knee varus, trunk lateral flexion to the tested leg, internal rotation

b. From initial contact to maximal knee flexion.

c. According to the Landing Error Scoring System definition, medial knee displacement represents the maximal knee valgus position (-).

Angle data from the three trials of each task were averaged for each participant. Means and standard deviations for dominant and non-dominant legs were calculated for each LESS item. Based on the kinematic differences between DLJL and SLJL rot $_{\text {tasks, original }}$ LESS thresholds [1,5], and current scientific evidence [3,8-18], the original LESS items from the DLJL task were modified to suit the SLJL $_{\text {rot }}$ task.

\section{Results}

The age, height, and mass (mean \pm standard deviation) of the 25 male volunteers were $23.6 \pm 4.1$ years (range 17 to 32 years), 182.2 $\pm 6.4 \mathrm{~cm}$, and $85.0 \pm 11.9 \mathrm{~kg}$; and of the 17 female volunteers were $22.2 \pm 5.7$ years (range 16 to 35 years), $169.1 \pm 6.0 \mathrm{~cm}$, and $63.7 \pm$ $6.8 \mathrm{~kg}$. Ninety-three percent of participants were right-leg domi- 
nant based on the preferred leg to kick a ball. All participants were physically active, involved in sport activity three times per week (median) on average for $6.7 \pm 4.4$ hours per week.

Kinematic parameters related to the LESS items extracted from 3D capture during DLJL and SLJL $\mathrm{L}_{\text {rot }}$ are summarized in Table 1. Table 2 presents the operational definitions of the original and modified LESS items with rationale for the suggested thresholds. The original LESS items (a) stance width: wide, (b) stance width: narrow, and (c) symmetric initial foot contact ${ }^{1}$ are not applicable for the SLJL $\mathrm{L}_{\text {rot }}$ and were removed from the modified LESS scoring sheet template. The original LESS items joint displacement and overall impression are subjective in nature, which is an obstacle for the automated quantification of the LESS [15]. Furthermore, the purely subjective rating or ranking of human movement to define performance [16] or injury risk [3] has been criticized and shown inaccurate. Therefore, these items were also removed from the modified LESS with a premise to yield higher sensitivity and predictive value.

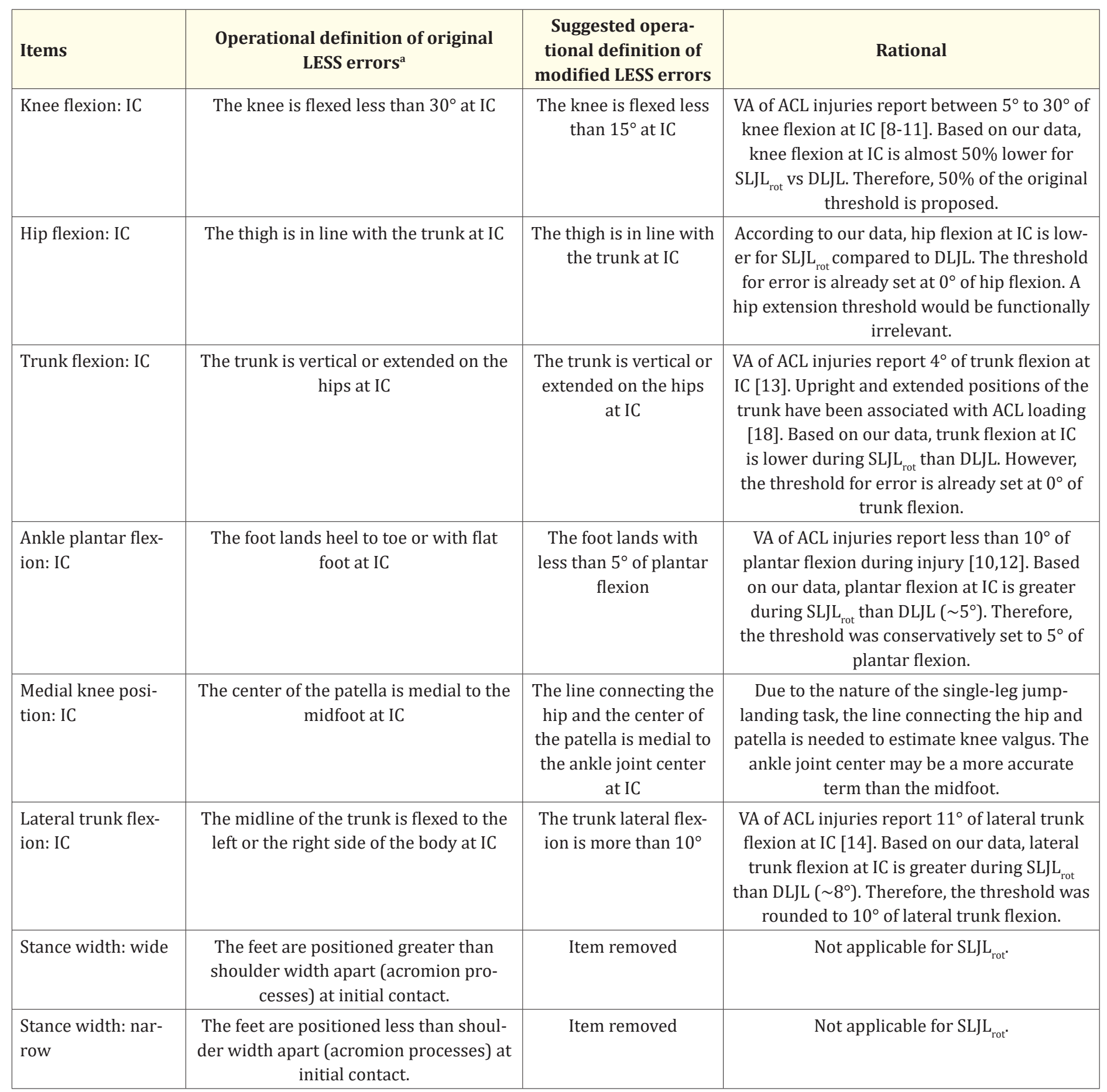




\begin{tabular}{|c|c|c|c|}
\hline $\begin{array}{l}\text { Foot position: exter- } \\
\text { nal rotation }\end{array}$ & $\begin{array}{l}\text { The foot is externally rotated more than } \\
30^{\circ} \text { between IC and MKF }\end{array}$ & $\begin{array}{l}\text { The foot is externally } \\
\text { rotated more than } 35^{\circ} \\
\text { between IC and MKF }\end{array}$ & $\begin{array}{l}\text { According to our data, foot external rotation is } \\
\text { greater during } \mathrm{SLJL} \text { rot } \text { than DLJL }\left(\sim 5^{\circ}\right) \text {. There- } \\
\text { fore, the threshold was changed to } 35^{\circ} \text { of foot } \\
\text { external rotation. }\end{array}$ \\
\hline $\begin{array}{l}\text { Foot position: inter- } \\
\text { nal rotation }\end{array}$ & $\begin{array}{l}\text { The foot is internally rotated more than } \\
30^{\circ} \text { between IC and MKF }\end{array}$ & $\begin{array}{l}\text { The foot is internally } \\
\text { rotated more than } 30^{\circ} \\
\text { between IC and MKF }\end{array}$ & $\begin{array}{l}\text { Our data showed similar foot internal rota- } \\
\text { tion between } \mathrm{SLJL}_{\text {rot }} \text { and DLJL. Therefore, the } \\
\text { original threshold for error was kept. }\end{array}$ \\
\hline $\begin{array}{l}\text { Knee flexion dis- } \\
\text { placement }\end{array}$ & $\begin{array}{l}\text { The knee flexes less than } 45^{\circ} \text { between IC } \\
\text { and MKF }\end{array}$ & $\begin{array}{l}\text { The knee flexes less } \\
\text { than } 30^{\circ} \text { between IC } \\
\text { and MKF }\end{array}$ & $\begin{array}{l}\text { According to our data, the knee flexion dis- } \\
\text { placement is } 70 \% \text { lower during } \text { SLJL }_{\text {rot }} \text { than } \\
\text { DLJL. Therefore, } 70 \% \text { of the original threshold } \\
\text { was used. }\end{array}$ \\
\hline $\begin{array}{l}\text { Trunk flexion dis- } \\
\text { placement }\end{array}$ & $\begin{array}{l}\text { The trunk does not flex more between IC } \\
\text { and MKF }\end{array}$ & $\begin{array}{l}\text { The trunk does not flex } \\
\text { more than } 5^{\circ} \text { between } \\
\text { IC and MKF }\end{array}$ & $\begin{array}{l}\text { According to our data, trunk flexion displace- } \\
\text { ment is greater during SLJL } L_{\text {rot }} \text { than DLJL }\left(\sim 5^{\circ}\right) \text {. } \\
\text { Therefore, the threshold was changed to } 5^{\circ} \text { of } \\
\text { trunk flexion displacement. }\end{array}$ \\
\hline $\begin{array}{l}\text { Medial knee dis- } \\
\text { placement }\end{array}$ & $\begin{array}{l}\text { At the point of maximum medial knee } \\
\text { position, the center of the patella is me- } \\
\text { dial to the midfoot }\end{array}$ & $\begin{array}{l}\text { At the point of maxi- } \\
\text { mum medial knee posi- } \\
\text { tion, the center of the } \\
\text { patella is medial to the } \\
\text { ankle joint center }\end{array}$ & $\begin{array}{l}\text { The ankle joint center may be a more accurate } \\
\text { term than the midfoot. The original threshold } \\
\text { was kept. }\end{array}$ \\
\hline Overall impression & $\begin{array}{l}\text { Excellent: the participant displays a } \\
\text { soft landing with no frontal-plane or } \\
\text { transverse-plane motion. Average: all } \\
\text { other landings. Poor: the participant dis- } \\
\text { plays large frontal-plane or transverse- } \\
\text { plane motion, or the participant displays } \\
\text { a stiff landing with some frontal-plane or } \\
\text { transverse-plane motion. }\end{array}$ & Item removed & See the rational above. \\
\hline $\begin{array}{l}\text { Lateral trunk flex- } \\
\text { ion displacement }\end{array}$ & & $\begin{array}{l}\text { The trunk lateral flex- } \\
\text { ion increases between } \\
\text { IC and MKF }\end{array}$ & $\begin{array}{l}\text { This item was added to the modified LESS } \\
\text { given the important role of trunk displace- } \\
\text { ment in ACL injuries }[14,17] \text {. }\end{array}$ \\
\hline
\end{tabular}

Table 2: Preliminary operational definitions of errors proposed for a modified Landing Error Scoring System applied to a rotated single-leg jump-landing with rationale for the suggested thresholds.

ACL, Anterior Cruciate Ligament; DLJL, double-leg jump-landing; IC, Initial Contact; LESS, Landing Error Scoring System; MKF, Maximal Knee Flexion; SLJLrot, Rotated Single-leg Jump-landing; VA, Video Analysis.

a. Adapted from Padua., et al. 2015. 
A scoring sheet template of the proposed modified LESS is presented in Table 3, as well as in Table 4 with pictorial representations of errors. The preliminary template consists of 13 items. The minimum score is 0 and maximum score is 12 errors, as it is not possible to score item 7 (i.e., foot external rotation) and 8 (i.e., foot internal rotation) at the same time. A higher score indicates a greater number of landing errors and poorer landing biomechanics.

\begin{tabular}{|c|c|c|c|}
\hline Items & Suggested operational definition of modified LESS errors & View & Scoring \\
\hline Knee flexion: IC & The knee is flexed less than $15^{\circ}$ at IC & Side & Yes $=1 ; \mathrm{No}=0$ \\
\hline Hip flexion: IC & The thigh is in line with the trunk at IC & Side & Yes $=1 ; \mathrm{No}=0$ \\
\hline Trunk flexion: IC & The trunk is vertical or extended on the hips at IC & Side & Yes $=1 ;$ No $=0$ \\
\hline Ankle plantar flexion: IC & The foot lands with less than $5^{\circ}$ of plantar flexion & Side & Yes $=1 ;$ No $=0$ \\
\hline Medial knee position: IC & $\begin{array}{l}\text { The line connecting the hip and the center of patella is medial to the } \\
\text { ankle joint center at IC }\end{array}$ & Front & $\mathrm{Yes}=1 ; \mathrm{No}=0$ \\
\hline Lateral trunk flexion: IC & The trunk lateral flexion is more than $10^{\circ}$ & Front & Yes $=1 ;$ No $=0$ \\
\hline Foot position: external rotation & The foot is externally rotated more than $35^{\circ}$ between IC and MKF & Front & Yes $=1 ; \mathrm{No}=0$ \\
\hline Foot position: internal rotation & The foot is internally rotated more than $30^{\circ}$ between IC and MKF & Front & Yes $=1 ;$ No $=0$ \\
\hline Knee flexion displacement & The knee flexes less than $30^{\circ}$ between IC and MKF & Side & Yes $=1 ;$ No $=0$ \\
\hline Hip flexion displacement & The thigh does not flex more on the trunk between IC and MKF & Side & Yes $=1 ;$ No $=0$ \\
\hline Trunk flexion displacement & The trunk does not flex more than $5^{\circ}$ between IC and MKF & Side & Yes $=1 ;$ No $=0$ \\
\hline Medial knee displacement & $\begin{array}{l}\text { At the point of maximum medial knee position, the center of the patella } \\
\text { is medial to the ankle joint center }\end{array}$ & Front & Yes $=1 ;$ No $=0$ \\
\hline Lateral trunk flexion displacement & The trunk lateral flexion increases between IC and MKF & Front & Yes $=1 ;$ No $=0$ \\
\hline Maximal score & & & 12 errors $^{\mathrm{a}}$ \\
\hline
\end{tabular}

Table 3: Scoring sheet template of the proposed modified Landing Error Scoring System applied to a rotated single-leg jump-landing. IC, Initial Contact; LESS; Landing Error Scoring System; MKF, Maximal Knee Flexion.

a. It is not possible to score error 7 and 8 at the same time. Therefore, the maximal score is 12 errors.

\begin{tabular}{|c|c|c|c|}
\hline Items & $\begin{array}{c}\text { Suggested operational definition } \\
\text { of modified LESS errors }\end{array}$ & Error present (1) & Error absent (0) \\
\hline Knee flexion: IC & $\begin{array}{c}\text { The knee is flexed less than } 15^{\circ} \\
\text { at IC }\end{array}$ & & \\
\hline Hip flexion: IC & $\begin{array}{c}\text { The thigh is in line with the trunk } \\
\text { at IC }\end{array}$ & & \\
\hline
\end{tabular}




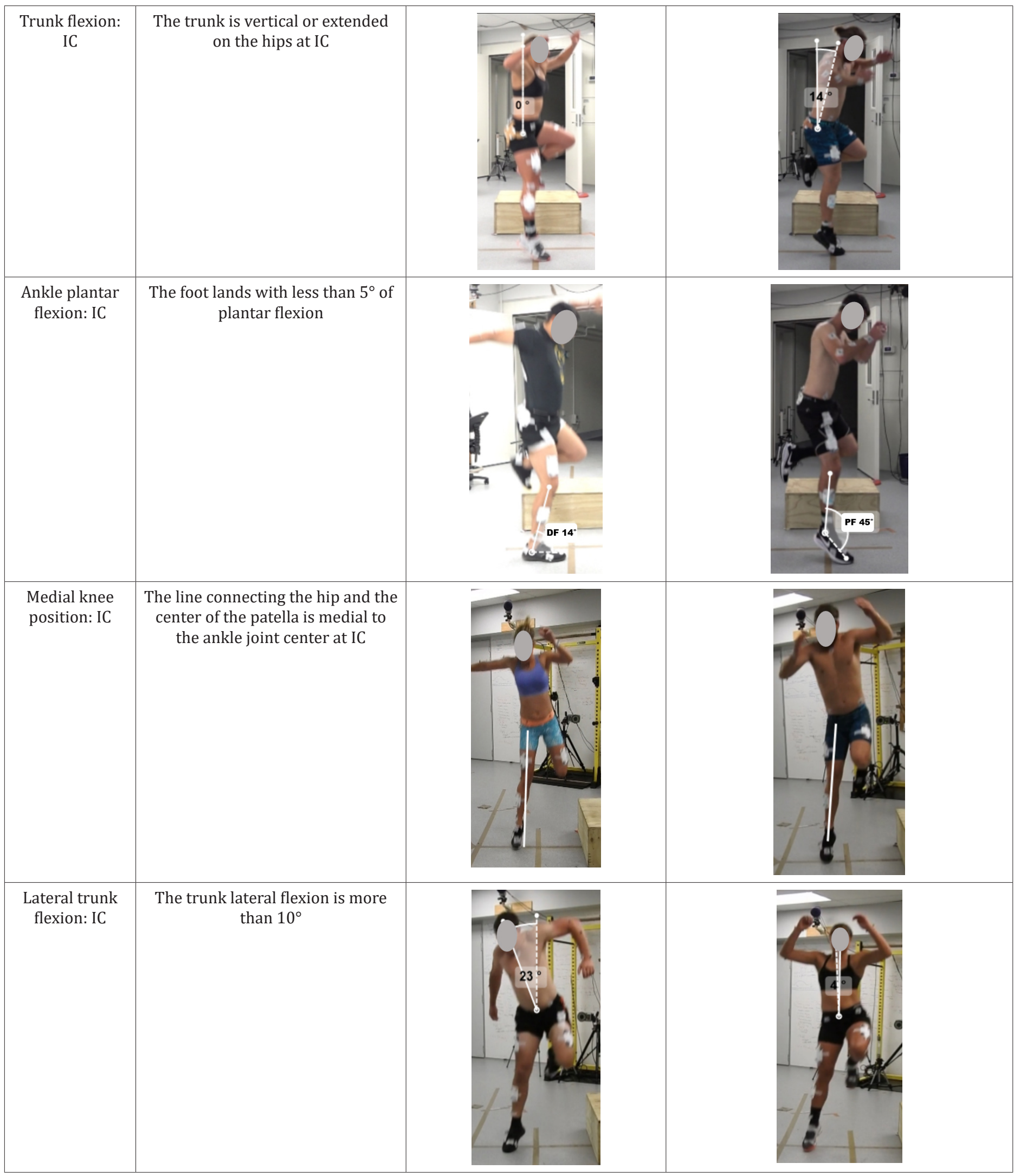




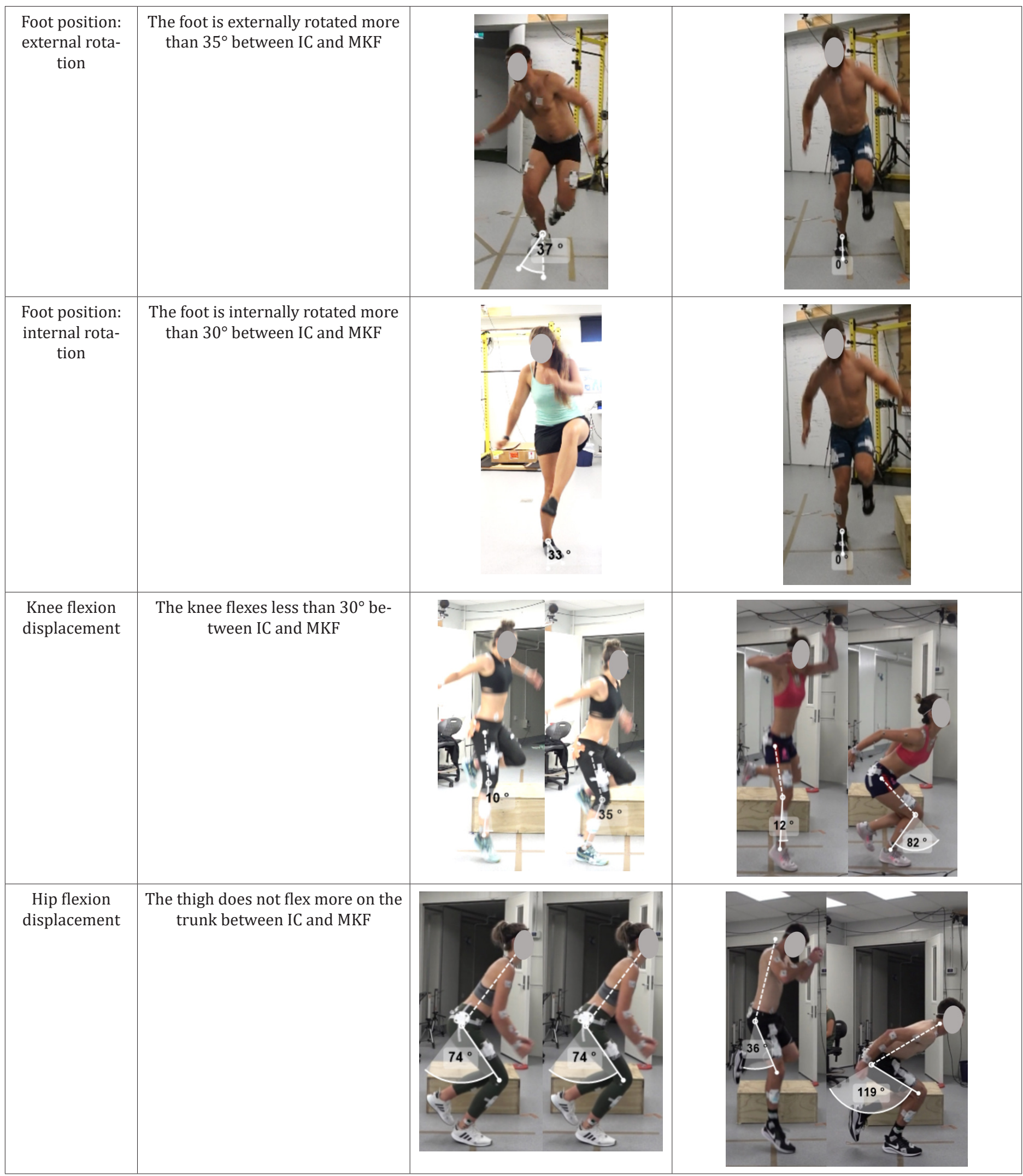




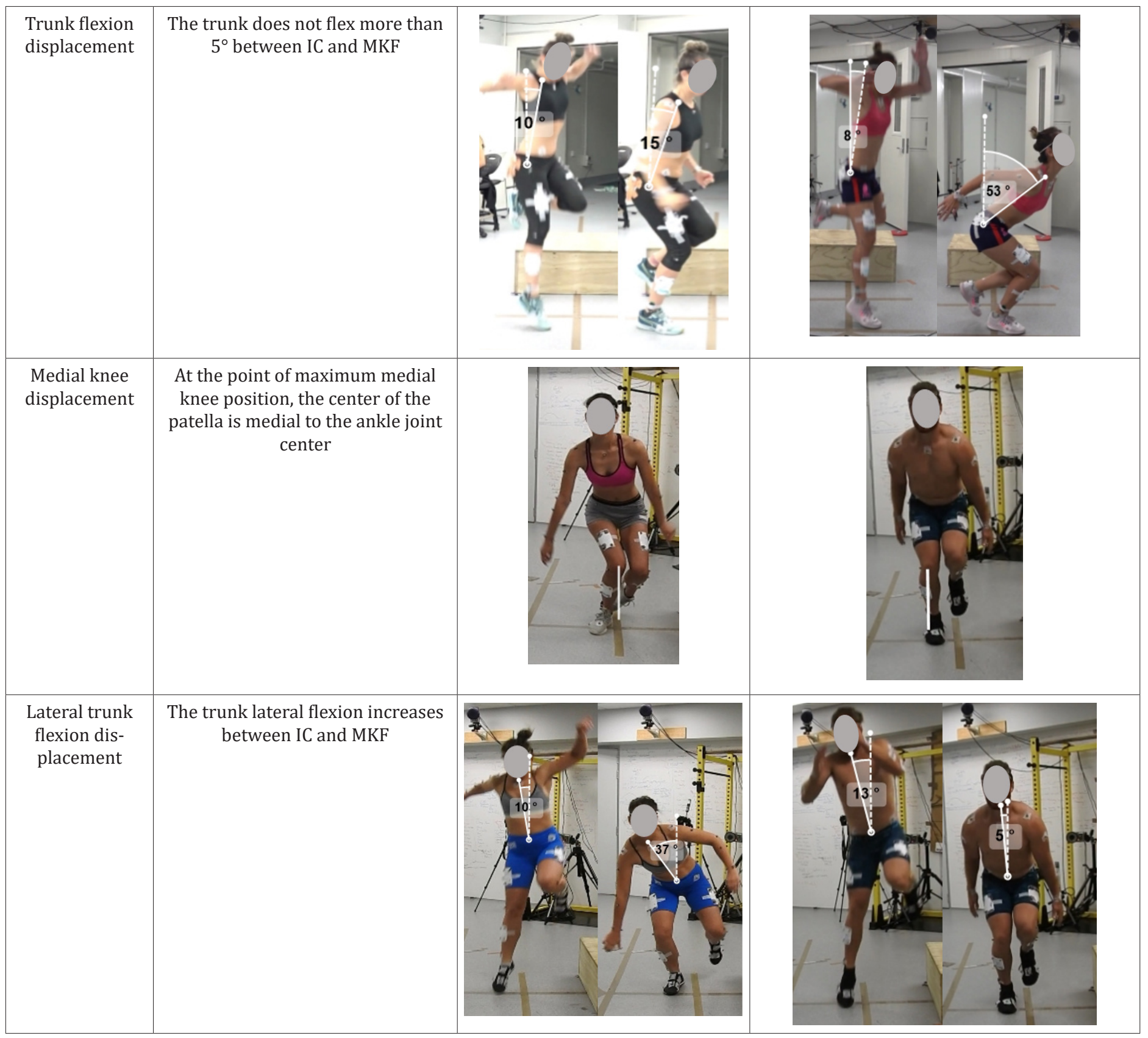

Table 4: Alternative scoring template for the proposed modified Landing Error Scoring System applied to the rotated single-leg jump-landing task with pictorial representation of errors.

IC, Initial Contact; LESS, Landing Error Scoring System; MKF, Maximal Knee Flexion.

\section{Discussion}

The aim of this technical report was to present a preliminary scoring template of a modified LESS applied to a SLJL $\mathrm{L}_{\text {rot }}$ task that is likely to be more sport-specific and ecologically valid for screening for injury risk than the original LESS applied to a DLJL task [1]. Based on our 3D motion data, original LESS thresholds [1,5], and current scientific evidence [3,8-18], we propose a modified LESS scoring tem- 
plate. This proposed template and associated thresholds require further scientific validation.

Similar to the original LESS, the modified LESS requires basic equipment for testing. More specifically, a $30 \mathrm{~cm}$-high box, a stadiometer to measure height, a measuring tape to set the landing distance to $25 \%$ of body height, and two standard video cameras are required, all of which are low-cost compared to other laboratorybased equipment used to evaluate movement. The SLJL $\mathrm{L}_{\text {rot }}$ task can be performed in a small area, and can be implemented in laboratories, clinics, gymnasiums, or outdoors. The time required to test is minimal given that participants are able to perform three repetitions of SLJL $_{\text {rot }}$ on both lower extremities in less than five minutes. Therefore, the modified LESS is feasible to conduct movement screening on large cohorts with limited time, space, and equipment. Furthermore, based on Hanzlíková., et al. [4], the SLJL ${ }_{\text {rot }}$ may be better suited than the DLJL to reveal movement patterns present during more challenging sport situations and therefore have a greater association with injury risk profiles specific to ACL and other non-contact lower extremity injuries in sport. On the other hand, due to its perceived level of difficulty [4], the SLJL $\mathrm{L}_{\text {rot }}$ may result in kinesiophobia in some individuals and an inability to perform this task. Hence, the SLJL $_{\text {rot }}$ may be inappropriate when screening older individuals or less physically active populations. Accurately determining angular measures from visual observations is challenging, with studies concluding that subjective ratings or rankings of human movement to define performance [16] or injury risk [3] are inaccurate. Therefore, we recommend assessing the modified LESS using a video analysis software for a more accurate quantification of angles and frameby-frame analysis. There are a number of free or low-cost software available shown to be valid and reliable for this purpose, suitable for clinical use [19].

To determine the thresholds for the modified LESS applied to the SLJL $\mathrm{rot}$, we compared lower extremity and trunk angles between DLJL and SLJL $\mathrm{L}_{\text {rot }}$ tasks using 3D motion analysis. This method is considered the "gold standard" tool for quantifying human movement non-invasively. We also based the new thresholds on previous studies [3,8-18], mainly video analyses, reporting joint angles during ACL injury situations. Finally, we also relied on the original LESS items and thresholds $[1,5]$. This three-pronged approach has several limitations. Even though the original LESS is a commonly used clinical and research tool shown to predict non-contact ACL injury in elite youth soccer players [5], the original LESS thresholds were based on clinical opinions rather than high-quality scientific evidence. Anoth- er limitation to our approach in setting the modified LESS thresholds is that the underpinning video analysis studies explored various injury situations, such as cutting, pivoting, and jump-landings [8-12,14] These injury situations may not correspond to "risky" biomechanics during the SLJL $\mathrm{L}_{\text {rot }}$. The ideal approach would be to base the modified LESS template and thresholds on high-quality prospective studies; however, such studies are currently not available and difficult to perform. Therefore, the suggested thresholds and individual items may change with new evidence.

It is essential that testing methods provide outcomes that are reproducible and valid so that changes in scores reflect meaningful changes in function of individuals and are able to identify individuals with differing abilities. Therefore, it is necessary to evaluate reliability and validity of the modified LESS. A systematic review exploring reliability and validity of the original LESS [20] concluded that the LESS is a reliable screening tool with moderate-to-excellent validity against 3D motion capture data for most of the items. Therefore, we expect the modified LESS screening tool to have similar levels of validity and reliability. Padua, DiStefano, Beutler, de la Motte, DiStefano, Marshall [5] identified 5 errors in the original LESS as an optimal cut point for distinguishing between athletes with low and high risk of ACL injury. The predictive value of this threshold in the context of ACL injury has not been confirmed by other studies [20]. Prospective studies are needed to assess the predictive ability of the modified LESS to detect non-contact ACL and other lower-extremity injury incidence and identify adequate thresholds for these injuries.

\section{Conclusion}

The modified LESS may be an appropriate clinical screening tool for assessing sport-related non-contact lower extremity injury risk in athletes. However, further research needs to evaluate the psychometric properties, specificity and sensitivity of the thresholds, and clinical merit of the modified LESS presented in this technical report.

\section{Bibliography}

1. Padua DA., et al. "The Landing Error Scoring System (LESS) is a valid and reliable clinical assessment tool of jump-landing biomechanics: the JUMP-ACL study". American Journal of Sports Medicine 37.10 (2009): 1996-2002.

2. Krosshaug T., et al. "The vertical drop jump is a poor screening test for ACL injuries in female elite soccer and handball players: a prospective cohort study of 710 athletes". American Journal of Sports Medicine 44.4 (2016): 874-883. 
3. Mørtvedt AI., et al. "I spy with my little eye... a knee about to go 'pop'? Can coaches and sports medicine professionals predict who is at greater risk of ACL rupture?" British Journal of Sports Medicine 54.3 (2020): 154-158.

4. Hanzlíková I., et al. "Which jump-landing task best represents lower extremity and trunk kinematics of unanticipated cutting maneuver?" Gait Posture 85 (2021): 171-177.

5. Padua DA., et al. "The Landing Error Scoring System as a screening tool for an anterior cruciate ligament injury-prevention program in elite-youth soccer athletes". Journal of Athletic Training 50.6 (2015): 589-595.

6. Cappozzo A., et al. "Position and orientation in space of bones during movement: anatomical frame definition and determination". Clinical Biomechanics 10.4 (1995): 171-178.

7. Grood ES and Suntay WJ. "A joint coordinate system for the clinical description of three-dimensional motions: application to the knee". The Journal of Biomechanical Engineering 105.2 (1983): 136-144.

8. Krosshaug T., et al. "Mechanisms of anterior cruciate ligament injury in basketball: video analysis of 39 cases". American Journal of Sports Medicine 35.3 (2007): 359-367.

9. Koga H., et al. "Mechanisms for noncontact anterior cruciate ligament injuries: knee joint kinematics in 10 injury situations from female team handball and basketball". American Journal of Sports Medicine 38 (11 (2010): 2218-2225.

10. Montgomery C., et al. "Mechanisms of ACL injury in professional rugby union: a systematic video analysis of 36 cases". British Journal of Sports Medicine 52.15 (2016): 994-1001.

11. Olsen O-E., et al. "Injury mechanisms for anterior cruciate ligament injuries in team handball: a systematic video analysis". American Journal of Sports Medicine 32.4 (2004): 1002-1012.

12. Boden BP., et al. "Video analysis of anterior cruciate ligament injury: abnormalities in hip and ankle kinematics". American Journal of Sports Medicine 37.2 (2009): 252-259.

13. Sheehan FT., et al. "Dynamic sagittal plane trunk control during anterior cruciate ligament injury". American Journal of Sports Medicine 40.5 (2012): 1068-1074.

14. Hewett TE., et al. "Video analysis of trunk and knee motion during non-contact anterior cruciate ligament injury in female athletes: lateral trunk and knee abduction motion are combined components of the injury mechanism". British Journal of Sports Medicine 43.6 (2009): 417-422.
15. Dar G., et al. "Concurrent criterion validity of a novel portable motion analysis system for assessing the Landing Error Scoring System (LESS) test". Sports Biomechanics 18.4 (2019): 426-436.

16. Cochrum RG., et al. "Visual classification of running economy by distance running coaches". European Journal of Sport Science (2020): 1-8.

17. Zazulak BT., et al. "Deficits in neuromuscular control of the trunk predict knee injury risk: prospective biomechanical-epidemiologic study". American Journal of Sports Medicine 35.7 (2007): 1123-1130.

18. Hashemi J., et al. "Hip extension, knee flexion paradox: a new mechanism for non-contact ACL injury". Journal of Biomechanics 44.4 (2011): 577-585.

19. Puig-Diví A., et al. "Validity and reliability of the Kinovea program in obtaining angles and distances using coordinates in 4 perspectives". PLoS One 14.6 (2019): e0216448.

20. Hanzlíková I and Hébert-Losier K. "Is the Landing Error Scoring System reliable and valid? A systematic review". Sports Health 12.2 (2020): 181-188.

\section{Assets from publication with us}

- Prompt Acknowledgement after receiving the article

- Thorough Double blinded peer review

- Rapid Publication

- Issue of Publication Certificate

- High visibility of your Published work

Website: www.actascientific.com/

Submit Article: www.actascientific.com/submission.php

Email us: editor@actascientific.com

Contact us: +919182824667 